\title{
From a literature review to a conceptual framework of enablers for smart manufacturing control
}

\author{
Rafael A. Rojas ${ }^{1}$ - Erwin Rauch ${ }^{1}$ (B) \\ Received: 1 September 2018 / Accepted: 7 May 2019 / Published online: 5 June 2019 \\ (C) The Author(s) 2019
}

\begin{abstract}
When cyber-physical systems (CPS) are connected to perform smart manufacturing, we have a cyber-physical production system (CPPS). In such systems, CPS collaborate in an intelligent way to obtain and maintain the optimum of the manufacturing process, handle disturbances and adapt to changing conditions. This work, based on a systematic literature review, shows current trends in cyber-physical production systems with a special focus on the role of connectivity and control systems in production. We are looking for the enablers of CPPS focusing on the current evolution of control systems in the smart factory of the future. As a result, a conceptual framework as well as a CPPS control system architecture for the introduction and organisation of enablers for CPPS is presented to support practitioners in the realisation of smart manufacturing control concepts.
\end{abstract}

Keywords Industry 4.0 $\cdot$ Smart manufacturing $\cdot$ Cyber-physical systems $\cdot$ Cyber-physical production systems $\cdot$ Internet of things $\cdot$ Systematic literature review

\section{Introduction and motivation}

The term Industry 4.0 may be understood as a new philosophy, which addresses each instance of the value chain of a product as a smart one, capable of making its own decisions and from which is possible to retrieve valuable information [1]. In particular, the manufacturing environment will be aware of all of these instances through new connectivity solutions based on the internet of things (IoT) and internet of services (IoS) [2]. A higher availability of information will make it possible to design resilient manufacturing systems, which can adapt to market demand, delays in the logistic chains and other disturbances to attain optimal values of the desired key performance indicators (KPIs).

The trend of Industry 4.0 intends to populate traditional shop floors with digitised systems capable of communicating their process parameters to their environment, to send their status and to express their availability for collaboration with

Erwin Rauch

erwin.rauch@unibz.it

1 Industrial Engineering and Automation (IEA), Faculty of Science and Technology, Free University of Bolzano, Piazza Università 5, 39100 Bolzano, Italy other machines or workers. Comparable solutions of networked sensors and actuators in industrial systems are not new. However, the increase of the processing capacity of modern embedded systems (ES) on the market has changed their focus to more than just processing and transmitting acquired data. The focus on design of ES has shifted from handling limited resources to an intimate interaction with physical processes and other peers through communication systems [3]. To emphasise the qualitative change in ES, the term 'cyberphysical system' has been introduced. Their processing capabilities and their connectedness make them able to exchange more structured information about their own impressions of the environment (environment-awareness) and their self-state (self-awareness) in order to make smart decisions autonomously. When objects in a manufacturing environment are endowed with cyber-physical capabilities and are connected to the same network, the possibilities for system automation are extended beyond the limits of traditional feedback control systems. In fact, in contrast to common stand-alone control systems, it will be possible with Industry 4.0 to design a body of collaborative autonomous CPS that regulates themselves, thanks to the capacity of each single entity to retrieve information from its peers and itself. This kind of control systems is called a networked control system (NCS) [4]. These types of networked systems are of crucial importance for the fourth industrial revolution, which requires, among other things, 
the connectivity and networking of all elements involved in a smart production system.

When integrated into a connected manufacturing environment, CPS replace the traditional automation pyramid and combine the IoT and automation systems to merge two domains that have been traditionally disjointed in industrial systems [5]. Specifically, we speak about two domains, the domain related to the processing of data to obtain valuable information (the information technology (IT) domain) and the domain related to the support of physical value creation in the manufacturing processes (the operation technology (OT) domain). This should be achieved through the integration of the enterprise resource planning systems (ERP), manufacturing execution systems (MES) and other software in a choreography of systems (vertical data integration) which are aware of the current state of each instance of the value chain (horizontal data integration). Following this idea, CPS will become the building block of the central entity of Industry 4.0, the smart factory, which is essentially CPPS.

The aim of this paper is to investigate the conceptual enablers of modern CPPS using a systematic literature review (SLR) as a basis to analyse the actual state of the art, to define future challenges and to develop an architecture for CPPS. Unlike other available reviews of Industry 4.0 [5-10], we addressed CPPS as a NCS and we focused on the interplay between control systems and IoT. Thanks to such a perspective, we provide an original literature review focusing on the interaction of the conceptual enabler of CPPS to show a global picture of the interaction between IT and OT in the factory of the fourth industrial revolution. Thus, this paper seeks to answer the following research questions:

RQ1: What is the actual state of the art of CPPS in the present scientific literature?

RQ2: Which of the enablers needed to realise smart CPPS and how can they be organised in CPPS framework?

RQ3: What are the future challenges that we need to be prepared to face in the design of CPPS?

This article is organised as follows. In Section 2, we examine the previous literature reviews on CPS in manufacturing to justify our motivation and to define the research gap. In Section 3, we describe our methodological approach based on SLR methodology and show the descriptive findings and a classification of the identified conceptual enablers of CPPS. In Section 4, we propose a framework and an architecture for CPPS enablers to support practitioners in the introduction of innovative manufacturing concepts and to provide a structured overview of the existing concepts and technologies. Finally, in Section 5, we investigate future directions in the design and realisation of CPPS before summarising the content of this research in Section 6.

\section{Antecedents, contributions and the research gap}

In the first step, we started with an analysis of the existing reviews on the application of CPS in general and in manufacturing. We have identified and distinguished two kinds of reviews (see Table 1): systematic literature review and traditional conceptual review. In a systematic literature review, inclusion and exclusion criteria are used to filter and evaluate what papers should be analysed [14]. A traditional conceptual review is based on the critical analysis of a selection of material. The purpose of such a review is to produce a better understanding of a certain topic. On one hand, we have systematic literature reviews [6-8]. On the other hand, we have conceptual reviews [5, 9-11]. Both groups create a classification of the topics that facilitate the implementation of CPS in industrial systems and address its current state.

The first group represents works using SLR methodology. The authors in [8] propose a set of representative technologies for smart manufacturing, which are CPS, cloud manufacturing, big data, IoT, smart sensors, additive manufacturing, energy efficiency and virtual and augmented reality. The authors in [6] used concepts related to CPS and manufacturing in their literature review, like the 5C layer architecture of Lee et al. [15] to classify the collected literature and to comment on the relevant results and findings for each layer. The authors in [7] structured their research using three research questions referring to which technologies are associated with Industry 4.0 in the construction industry: 'What is the current state of these technologies?', 'Which technologies have already been adopted?' and 'Which far-reaching implications do they imply?'

The second group is based on traditional conceptual reviews. The authors in $[5,9]$ explored the roots of CPPS in the interplay between computer sciences, IT and manufacturing. In addition, the authors underlined the importance in communication systems, where they focus on the qualitative differentiation of data flows and architectural approaches, infrastructure solutions and possibilities as service-oriented architectures, manufacturing service bus and plug-and-work technologies. Similarly, the authors in [11] examined the key aspects of industrial CPS and illustrated four European projects dedicated to the implementation of CPPS (the European innovation project SOCRADES, project GRACE, project IMCAESOP and project ARUM). The authors in [10] describe their view on the drivers and initiatives for the implementation of CPS in manufacturing systems as well as the barriers for their realisation. They based on [16]'s study to identify the aspects that characterise CPS and enumerate the drivers of CPPS as the analysis of the systems of systems (SoS) [17], IoT, cloud technologies and Industry 4.0. Finally, a view on challenges and future research directions on CPPS was given, where the main trends are self-organising systems, context- 
Table 1 Summary of findings of already existing literature review papers on CPPS

\begin{tabular}{|c|c|c|c|}
\hline Reference & $\begin{array}{l}\text { Review } \\
\text { type }\end{array}$ & Authors, title and source & Focus of the literature review \\
\hline$[8]$ & $\begin{array}{l}\text { Systematic } \\
\text { literature } \\
\text { review }\end{array}$ & $\begin{array}{l}\text { Kang et al. (2016): Smart manufacturing: Past research, } \\
\text { present findings, and future directions. International Journal } \\
\text { of Precision Engineering and Manufacturing-Green } \\
\text { Technology, 3(1):111-128. }\end{array}$ & $\begin{array}{l}\text { Proposition of a set of representing technologies for smart } \\
\text { manufacturing, which are CPS, cloud manufacturing, big } \\
\text { data, IoT, smart sensors, additive manufacturing, energy } \\
\text { efficiency and virtual and augmented reality. }\end{array}$ \\
\hline$[6]$ & $\begin{array}{l}\text { Systematic } \\
\text { literature } \\
\text { review }\end{array}$ & $\begin{array}{l}\text { Trappey et al. (2016): A review of technology standards and } \\
\text { patent portfolios for enabling cyber-physical systems in } \\
\text { advanced manufacturing. IEEE Access, 4:7356-7382. }\end{array}$ & $\begin{array}{l}\text { Use of the } 5 \mathrm{C} \text { layer architecture to classify the collected } \\
\text { literature and comment the relevant results and findings for } \\
\text { each layer. The review gives a critical evaluation of } \\
\text { international standards and the intellectual property } \\
\text { contained in CPS patents. }\end{array}$ \\
\hline$[7]$ & $\begin{array}{l}\text { Systematic } \\
\text { literature } \\
\text { review }\end{array}$ & $\begin{array}{l}\text { Oesterreich and Teuteberg (2016): Understanding the } \\
\text { implications of digitisation and automation in the context of } \\
\text { industry 4.0: A triangulation approach and elements of a } \\
\text { research agenda for the construction industry. Computers in } \\
\text { Industry, 83:121-139. }\end{array}$ & $\begin{array}{l}\text { Description of industry } 4.0 \text { technologies associated to } \\
\text { construction industry. They identify the following clusters: } \\
\text { smart factory, simulation, modelling, digitalization, and } \\
\text { virtualization. The comprehensive systematic literature } \\
\text { review is combined with a case study research. }\end{array}$ \\
\hline [9] & $\begin{array}{l}\text { Conceptual } \\
\text { literature } \\
\text { review }\end{array}$ & $\begin{array}{l}\text { Monostori (2014): Cyber-physical production systems: Roots, } \\
\text { expectations and challenges. Procedia CIRP, 17:9-13. }\end{array}$ & $\begin{array}{l}\text { Focus is on the interplay between computer science, IT and } \\
\text { manufacturing. Future challenges are in context-adaptive } \\
\text { and autonomous systems, cooperative production systems, } \\
\text { prediction of dynamic systems, fusion of real and virtual } \\
\text { systems, human-machine symbiosis and robust scheduling. }\end{array}$ \\
\hline$[5]$ & $\begin{array}{l}\text { Conceptual } \\
\text { literature } \\
\text { review }\end{array}$ & $\begin{array}{l}\text { Monostori et al. (2016): Cyber-physical systems in } \\
\text { manufacturing. CIRP Annals - Manufacturing Technology, } \\
\text { 65(2):621-641. }\end{array}$ & $\begin{array}{l}\text { Special focus on real-time data and standardisation in } \\
\text { communication within CPPS to enable plug-and-work } \\
\text { solutions. }\end{array}$ \\
\hline$[10]$ & $\begin{array}{l}\text { Conceptual } \\
\text { literature } \\
\text { review }\end{array}$ & $\begin{array}{l}\text { Wang et al. (2015): Current status and advancement of } \\
\text { cyber-physical systems in manufacturing. Journal of } \\
\text { Manufacturing Systems, 37(Part 2):517-527. }\end{array}$ & $\begin{array}{l}\text { Review on drivers, initiatives and barriers in the } \\
\text { implementation of CPS in manufacturing. Future research } \\
\text { challenges will be self-organising manufacturing systems, } \\
\text { context and situation aware control systems, symbiotic } \\
\text { human-robot collaboration and CPS methodologies. }\end{array}$ \\
\hline$[11]$ & $\begin{array}{l}\text { Conceptual } \\
\text { literature } \\
\text { review }\end{array}$ & $\begin{array}{l}\text { Leitão et al. (2016): Industrial automation based on } \\
\text { cyber-physical systems technologies: Prototype } \\
\text { implementations and challenges. Computers in Industry, } \\
81: 11-25 \text {. }\end{array}$ & $\begin{array}{l}\text { Description of the following key aspects of industrial CPS in } \\
\text { four European projects dedicated to the implementation of } \\
\text { CPPS: multi-agent systems, service-oriented-architecture } \\
\text { and cloud technologies. }\end{array}$ \\
\hline$[12]$ & $\begin{array}{l}\text { Conceptual } \\
\text { literature } \\
\text { review }\end{array}$ & $\begin{array}{l}\text { Wang (2017): An overview of internet-enabled cloud-based } \\
\text { cyber manufacturing. Transactions of the Institute of } \\
\text { Measurement and Control, 39(4):388-397. }\end{array}$ & $\begin{array}{l}\text { Latest advancement of internet-enabled cloud-based cyber } \\
\text { manufacturing and new approaches for } \\
\text { hardware-in-the-loop real-time applications, including } \\
\text { cloud-based remote monitoring and control of industrial } \\
\text { robots, remote assembly in a cyber-physical environment, } \\
\text { and a cloud robotic system for energy-efficient operation. }\end{array}$ \\
\hline$[13]$ & $\begin{array}{l}\text { Conceptual } \\
\text { literature } \\
\text { review }\end{array}$ & $\begin{array}{l}\text { Thoben et al. (2017): 'Industrie } 4.0 \text { ' and smart } \\
\text { manufacturing-a review of research issues and application } \\
\text { examples. International Journal of Automation Technology, } \\
\text { 11(1):4-16. }\end{array}$ & $\begin{array}{l}\text { Overview of the Industrie } 4.0 \text { and smart manufacturing } \\
\text { programs; analysis of the application potential of CPS } \\
\text { starting from product design through production and } \\
\text { logistics up to maintenance. }\end{array}$ \\
\hline
\end{tabular}

and situation-aware control, symbiotic human-robot collaboration, security and the development of implementation methods for CPS. The authors of the review in [12] include case studies showing that an integrated cyber-physical system consumes less internet traffic than traditional systems. The authors of [13] analysed different application scenarios for CPPS in the sense of cyber-physical logistics systems, safe human robot interaction and video surveillance. They identified a need for future areas of a technical nature (standards, data analytics, data security and quality, sensors and actuators), of a methodological nature (reference models, visualisation, service/app marketplaces, requirements engineering) and of a business nature (privacy, investment, servitised business models).

In this work, we have a similar focus to the previousmentioned reviews. However, we have investigated the underlying conceptual enablers for the coordination and orchestration of the different emerging technologies that converge to realise a CPPS. In fact, in the previous reviews, these technology enablers are categorised under conceptual clusters with such a granularity that makes a general view of the interaction between each of them difficult. As a consequence, these clusters appear separately and their combination inside a CPPS remains obscure. It is our interest to contribute with this work 
by providing a global picture of the transition of information, which includes the possibilities of smartness, modularity, event-orientation and robustness of a smart factory, i.e. a CPPS.

In this work, three fundamental types of layers are used to explain the structure of CPS [18]: physical, platform and software layer. The first and the second constitute the physical part of the CPS. Meanwhile, the physical layer is related to the physical world, which is subject to the interaction whit the CPS (OT), and the platform layer constitutes the hardware support of the software layer and communications. This distinction becomes fundamental in CPS due to the qualitative different influences in the software layer between these two layers. The software layer is where the virtual representation lies and decision-making is done. However, these three layers do not completely distinguish a CPS from an ES, so we desire to further underline the qualitative transition from ES to CPS focusing on the centrality of the intimate interaction between the cyber and physical domains, and its possibility of sharing information with other CPS's. On the one hand, (i) we have a low-level control system implemented in CPS and involving the three layers. It requires an accurate digital representation of the physical context of the CPS to retrieve a significant picture of the complete situation and to apply the correct control actions to drive the physical context in accordance with the desired behaviours. On the other hand, (ii) the quality is related to the software and platform layer, and it not only expands the horizon of the traditional stand-alone control systems, but also introduces the challenge of addressing more complex systems, translating information from heterogeneous systems and conveying the right information where it is required.

\section{Research method and descriptive findings}

In this section, we will first describe the selected research methodology using SLR as the review technique. Afterwards, a descriptive sample overview shows and comments on the quantitative findings of the collected literature. We applied SLR in our study because it is based on a systematic, method-driven and replicable approach [19]. According to [20], SLR is characterised by a scientific and transparent process that aims to minimise bias through exhaustive literature searches and by providing an audit trail of the reviewer's procedures. Compared with other instruments, like co-citation analysis, SLR takes into account every source beyond the number of citations, which naturally are relatively low for recently published works. As research on CPPS is relatively new and an emerging field, this factor plays an important role in the selection of the research methodology.

There are several studies on how to conduct a SLR (e.g. [19, 21-23]). In our research, we applied the SLR approach as suggested by [22]. Based on this reference, we defined the following four consecutive steps for our study:

- Step 1: Establishing the research objectives;

- Step 2: Defining the conceptual boundaries of the research;

- Step 3: Setting out the data collection by defining the inclusion/exclusion criteria;

- Step 4: Reporting the validation efforts.

\subsection{Research objectives}

The objectives of this research were deduced from the research questions described in the introduction. Our aim is to analyse the current knowledge and state of the art regarding CPPS, with special emphasis on the enablers for smart manufacturing control systems. In particular, we want to understand how these enablers can be categorised and what their importance is regarding the implementation of networked control systems in smart factories.

\subsection{Conceptual boundaries}

This research aims to analyse cyber-physical production systems. Thus, the setting of the conceptual boundaries was based on the terms 'cyber-physical' combined with 'production system'. As a production process can be further subdivided into manufacturing and assembly processes [24], the terms 'manufacturing system' and 'assembly system' were further considered to define the conceptual boundaries.

\subsection{Inclusion and exclusion criteria}

In addition to the conceptual boundaries, several search criteria, in terms of database, search terms and publication period, were defined. In particular, we used Scopus as the electronic database for the keyword search, which we identified as being the most relevant for publications in the engineering and manufacturing area. A previous checking of other sources such as ISI Web of Knowledge, Science Direct and Emerald did not show any major changes in relation to adding to the sources. Therefore, we decided to conduct the SLR with the Scopus database as it represents the most relevant source for our purpose.

Table 2 shows the applied inclusion and exclusion criteria in relation to the search query. As mentioned above, we used the following search terms: 'cyber-physical', 'cyberphysical', 'cyber physical' in combination (Boolean AND) with 'production system', 'manufacturing system', and 'assembly system'. The sub-areas included all engineering fields as well as related fields. We limited our search to published works with a starting year of 2012 and an end date of December 31st, 2017. A limitation to English papers was only set because we intended to focus on 
Table 2 Search terms and search limitation

\begin{tabular}{|c|c|c|}
\hline Limitation & Criteria & Count \\
\hline Source & Scopus & - \\
\hline Search in & Article title, Abstract, Keywords & - \\
\hline Search terms and connections & $\begin{array}{l}\text { ‘Cyberphysical production system’ OR ‘Cyber-physical production system’ } \\
\text { OR ‘Cyber pphysical production system’ OR ‘Cyberphysical manufacturing } \\
\text { system’ OR ‘Cyber-physical manufacturing system’ OR ‘Cyber physical } \\
\text { manufacturing system’ OR ‘Cyberphysical assembly system’ OR } \\
\text { ‘Cyber-physical assembly system’ OR ‘Cyber physical assembly system’ }\end{array}$ & 1280 \\
\hline Time & $2012-2017$ & 1233 \\
\hline Source type & $\begin{array}{l}\text { Conference proceedings, journal contribution (excluding book chapters, books, } \\
\text { editorials, short surveys, trade journals) }\end{array}$ & 1035 \\
\hline Language & English & 975 \\
\hline \multirow[t]{2}{*}{ Screening } & First phase of coding: examination of title and abstract & 310 \\
\hline & Second phase of coding: examination of the whole paper & 165 \\
\hline
\end{tabular}

Count refers to the studies left after applying the search limitation

internally recognised work exclusively. Regarding the type of publication, (i) journal contributions as well as (ii) conference papers were included in the search as CPPS is an emergent topic and thus highly relevant work could be published as a conference paper and not yet as a journal contribution.

\subsection{Validation of the search results}

The appropriateness of the identified literature references to the aims of the study is crucial for every SLR. Often, the search results treat the subject of the SLR study as only incidental or superficial. To ensure the appropriateness of the search results, we applied a relatively straightforward coding scheme which evaluated the appropriateness of a search result using a score of 1-3 (where 3 denotes high, 2 denotes medium and 1 denotes low). The screening was carried out in two phases. In the first phase, only the title and abstract were read. In the second phase, the whole paper was examined. We calculated an inter-rater reliability for each paper by evaluating the difference in scoring. Where the three independent raters came to the same conclusion, i.e. zero differences or the highest inter-rater reliability, the papers were directly included into the analysis. Papers where differences in the coding occurred were excluded if a successive iteration did not result in $100 \%$ agreement between the three researchers.

\subsection{Descriptive findings}

In total, we analysed 975 papers of which 810 were scrapped due to the screening as described in 3.4. The remaining 165 works represent a period from 2012 to 2017. Most of the research occurred at conference proceedings (67\%), while publications in journals showed a lower value $(33 \%)$ (see Table 3). Such a high rate of conference papers indicates that the field is in the developing stage and the results are beginning to be settled at the journal level.

Table 4 illustrates the distribution of the journals, where journal level contributions were published. Most of works on journal level were published in At Automatisierungstechnik, Computers in Industry, the Journal of Manufacturing Systems, Production Engineering, CIRP Annals Manufacturing Technology, the International Journal of Manufacturing Research, Sensors, the Journal of Computing and Information Science in Engineering, the International Journal of Computer Integrated Manufacturing and the International Journal of Modern Manufacturing Technologies, with the latter making up $59.26 \%$ of the total journal publications.

Further analysis was conducted extracting the used keywords in the identified papers. Figure 1 shows the frequency distribution of the keywords with a frequency of ten or higher. In total, 2.533 keyword nominations were analysed with 1.609 different keywords. The most important keywords have been illustrated in Fig. 1 and represent 17\% (423 nominations) of the total used keywords.

\subsection{Content analysis to identify enablers for smart manufacturing control}

As it is recognised in $[1,2,5]$, the trend of Industry 4.0 and the introduction of CPPS is a convergence of advanced

Table 3 Distribution of published works according to publication type

\begin{tabular}{lll}
\hline Source type & Number & Percent \\
\hline Conference papers & 111 & 0.67 \\
Journal articles & 54 & 0.33 \\
Books and book series & 0 & 0 \\
Trade journals & 0 & 0 \\
\hline
\end{tabular}


Table 4 Article source of published journal contributions

\begin{tabular}{llll}
\hline Journal & Number & Percent & Cum. Percent \\
\hline At Automatisierungstechnik & 5 & 9.26 & 9,26 \\
Computers in Industry & 5 & 9.26 & 18,52 \\
Journal of Manufacturing Systems & 4 & 741 & 25,93 \\
Production Engineering & 4 & 7.41 & 33,33 \\
CIRP Annals Manufacturing Technology & 4 & 7.41 & 40,74 \\
International Journal of Manufacturing Research & 2 & 3.70 & 44,44 \\
Sensors & 2 & 3.70 & 48,15 \\
Journal of Computing and Information Science in Engineering & 2 & 3.70 & 51,85 \\
International Journal of Computer Integrated Manufacturing & 2 & 3.70 & 55,56 \\
International Journal of Modern Manufacturing Technologies & 2 & 3.70 & 59,26 \\
Other & 22 & 40.74 & 100,00 \\
\hline
\end{tabular}

technologies in several fields, rather than a single innovation. We want to search for general conceptual frameworks where the main concepts available in the collected literature may be classified with respect to an original lecture as we have previously explained. In order to be able to identify and classify the main enablers of smart manufacturing control, we have carried out a content analysis of the filtered papers. Based on this approach, we have identified the following six main clusters of enablers for CPPS, as shown in Table 5.

1. Multi-agent systems and holonic manufacturing: In the first cluster, we want to investigate the meaning of 'smartness' and the 'intelligent collaboration' of CPS inside a smart factory. This characterisation is pervasive in CPPS literature, but it is not always clearly explained. In manufacturing systems, these features were explored under the term holonic manufacturing systems (HMS), introduced in [34] and implemented in manufacturing in the early 1990s [25]. A holon is an autonomous and cooperative building block within a holonic system [35] (i.e. a body of holons). The authors in [39] and [40] propose that a network of holons is a constitutive element of a CPPS. From the perspective of basic sciences, the field of artificial intelligence (AI) gave birth to the concept of multiagent systems (MAS), during the research of the same features of holons in software systems. An agent may be

\section{keyword frequency (number of nominations in the identified works)}

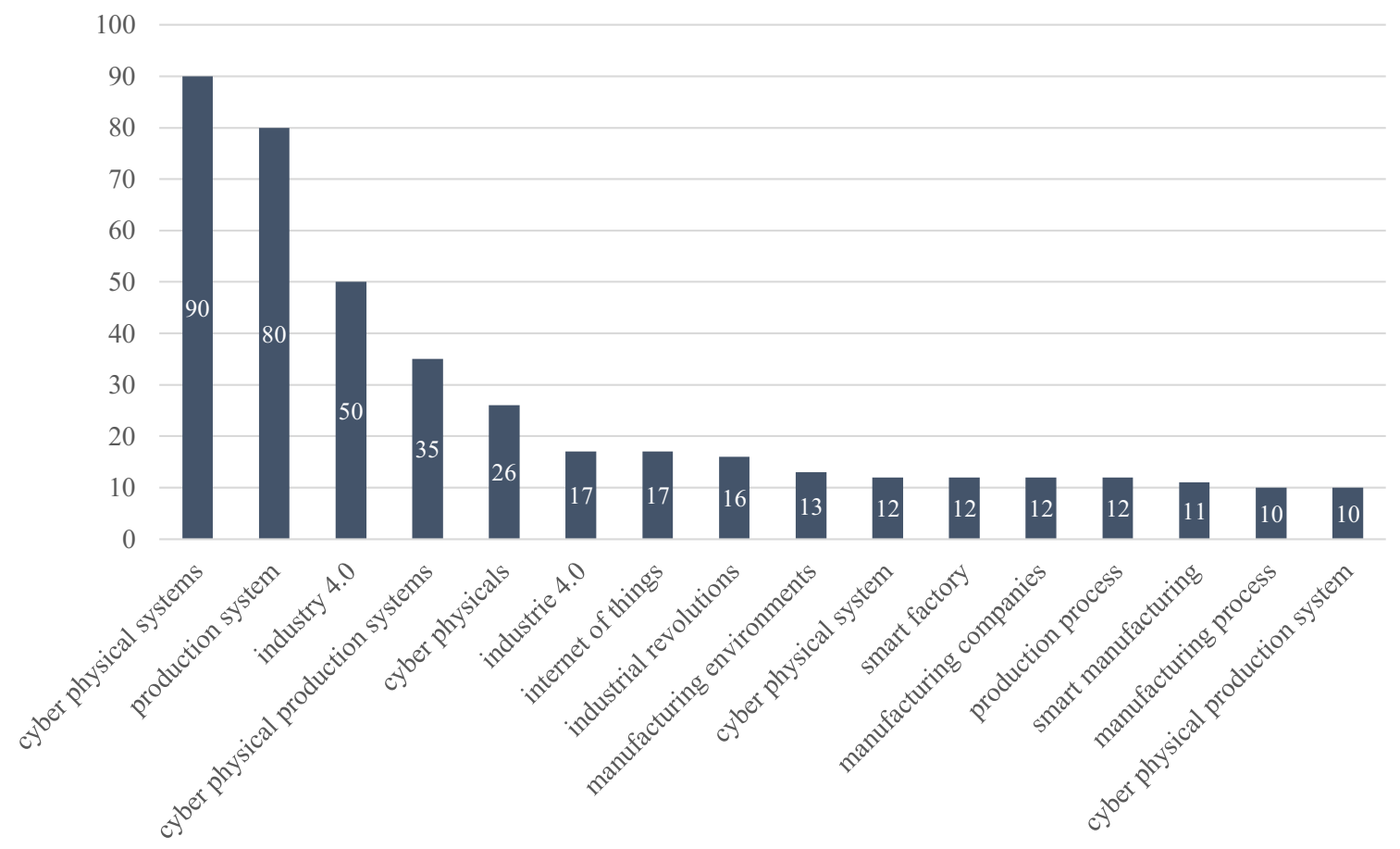

Fig. 1 Keyword frequency 
Table 5 Literature-based classification of six clusters of enablers for smart manufacturing control

\begin{tabular}{llll}
\hline No. & Cluster & Main relevant references & \#works \\
\hline 1 & Multi-agent systems and holonic manufacturing & {$[5,25-40]$} & 17 \\
2 & Integration and interoperability & {$[11,41-77]$} & 38 \\
3 & Data analysis, big data and machine learning & {$[30,33,63,78-92]$} & 18 \\
4 & Cloud computing & {$[10,40,54,63,91-110]$} & 24 \\
5 & Human-machine interaction & {$[111-139]$} & 29 \\
6 & Cyber security & {$[140-156]$} & 17 \\
\hline
\end{tabular}

defined as a system that is situated in an environment that is capable of exerting autonomous actions in such an environment in order to meet its design objectives [27]. CPS share the following characteristics with agents in a MAS [26]: (i) they are self-aware and ambient-aware, (ii) they react timely to ambient variations, (iii) they exhibit goaloriented behaviour, and (iv) they interact with their peers. The authors like [5; 28-30] propose MAS technology as the main enabler of smart collective behaviour in CPPS. The authors in [38] confirm that agents and holons are complementary concepts inside a CPPS. They propose a CPS architecture that combines both paradigms, agents and holons. With the aforementioned combination, it is possible to identify CPS as holons or agents. We confirm with our review that both holonic systems and multi-agent systems are part of the same conceptual enabler of CPPS, which provides the foundations to have flexible and reconfigurable manufacturing systems composed by CPS which are capable of negotiating and arriving at agreements and to coordinate smart actions.

2. Integration and interoperability: Our second cluster is related to the technical and architectural enablers, which permit the sharing of information between different nodes inside a CPPS. This cluster addresses the implementation of an IoT in a body of CPS to achieve the pervasive availability of the information, addressing the issue of the interoperability of data representation between different systems, the network architectures and details on the communication infrastructure at the physical and logical level. The concept of integration may be understood as the process of ensuring that the interactions between entities in a system are those necessary to achieve specific objectives [41]. At this point, we introduce also the concept of interoperability, which is referred to as the ability of one system to process and use the information of another system [55]. Further, we regard the problem of the integration of CPS as a problem of interoperability between digital systems. We have identified different models of integration in literature: (i) vertical integration and (ii) horizontal integration. The need for vertical integration can appear between the machine level and a MES level [3]. The authors in [61] describe another example of vertical integration, where mobile robots are integrated for the determination of information about the geometric location and volumetric information of parts. Horizontal integration means the integration of information systems along a supply and/or value chain [63, 64].

3. Data analysis: This cluster discusses how information may be gathered from a CPPS and which knowledge may be retrieved from it. The methods used to retrieve information may be based on models, or not. Among the model-based approaches, the simulation systems have acquired importance in CPPS literature. Such model-based or simulation approaches in CPPS are addressed in [78-80]. Authors in $[81 ; 82 ; 84]$ propose a mathematical-physical model to increase the quality of production in the context of CPS. In $[63,83]$, the authors exploit a simulation-based model of a CPPS to achieve supply-demand matching. On the other hand, techniques based on AI such as machine learning (ML) are a possibility to analyse information in the absence of models. ML algorithms in CPPS have been addressed in [87, 88] using ML techniques for the automatic detection of anomalous and sub-optimal plant situations. Features like AI or ML are of capital importance when analysing the large amounts of unstructured and heterogeneous data produced by the pervasive availability of information in CPPS. To deal with this, big data provides a family of techniques for data collection and interpretation focused on providing recommendations for decision-making. The authors in $[90 ; 91]$ present how the adoption of IoT in manufacturing, considering sensory systems and mobile devices will generate industrial big data. The authors in [92] present the application of big data analytics to extract the influence of the parameters of a CPPS on its behaviour. The authors in [91] describe the techniques used to manage data volume and velocity during the data collection phase in a big data environment.

4. Cloud computing: Thanks to the availability of internet in CPPS shop floors, it will be possible to retrieve information and resources from remote third parties. Unlike the cluster of integration and interoperability that addresses connectivity in a wide sense, the cluster of cloud computing is specifically related to the technologies used for 
providing services remotely through the internet. The concept of cloud manufacturing has evolved parallel to that of Industry 4.0, with [91] proposing a new paradigm to organise manufacturing resources over networks [92] based on new concepts in information and communication technologies (ICT) and the internet. Cloud may be understood as a digital distributed platform providing easily usable and accessible virtual resources such as hardware, data analysis platforms and services [93]. In [98, 99], cloud computing was identified as a key enabler of CPPS. It can be considered as a gateway to integrate a body of CPS into the horizontal value chain [100].

5. Human-machine interaction: In Industry 4.0, humans play a central role in the production systems and processes. In such an anthropocentric production system, humans are in synergy with robots and other machines, which increases their capabilities through interactive and supporting tasks. This category reviews the main technologies which allow the integration of humans into CPPS. To support humans, CPS need human machine interaction (HMI) methods, as explored in $[116,117]$. In their works, they describe how HMI methods have evolved from indicator lights, buttons and levers through to every day graphical user interfaces (GUI), keyboards, mouse and touchscreens, before arriving to the concept of multimodal interfaces [118], where the voice, hands, and entire body become a communication channel. An example of modern ways of HMI is automatic speech recognition [119]. Another example is visual gesture control using expressive and meaningful body motions [123, 128]. Further, we can have physical human-robot interaction as, under the perspective of the multimodal interface, physical contact may be used to create an interaction interface for CPS. Such a concept has been extensively explored in robotics, in particular, the field of collaborative robotics [134].

6. Cyber security: Due to the connectivity of CPPS with worker, material, machines, IT systems and also external systems, cyber security is a significant topic, in today's research of the factory of the future. In this cluster, we collect several contributions regarding analysis and implementation of cyber security in CPPS. It has been recognised in [140-142] that the concept of security takes a new dimension, when referring to CPS and CPPS. The intrinsic heterogeneity of communication technologies and data exchanges in CPPS are a fertile ground for weak links. In fact, it is recognised in $[143,144]$ that one of the major drawbacks of implementing ITC technologies in manufacturing is the issue of cyber security. Several attacks in CPS have been reported in [145-147] with negative consequences and the associated economic costs.

\section{Development of a framework for cyber-physical production systems}

The interaction of the previously described conceptual clusters is only possible thanks to connectivity. In fact, we retain the cluster of integration and interoperability as the central pivot that enables the interaction of the other conceptual clusters through IoT. Given this importance, we designed a conceptual framework for CPPS based on a three tier architecture [42, 66] which consists of a logical subdivision of the nodes in the network in three 'tiers', in accordance with their communication needs and functional characteristics (see Fig. 2). At the lower level, we have the 'edge tier', which is in direct contact with the physical world and performs lower level control tasks. The 'platform tier' implements functional capabilities to enable the operability of the hardware and to collect information from all instances of the CPPS, providing high-level analysis and intelligence about the overall system. The 'enterprise tier' implements the function of data analytics and highlevel decision-making. The three tier architecture proposes a specific kind of network for each tier that is suitable for the type of digital system lying on the tier. Every actor in a CPPS involves nodes and, at the same time, a holon with a digital part associated with each node. Each tier is characterised by containing qualitatively different holons. At the edge tier, almost every holon has a physical part, i.e. a CPS that enables the creation of physical value implementing OT. At the other tiers, most of the holons have only a digital part implementing IT for data processing, and to retrieve valuable information for high-level decision-making.

CPPS are possible, thanks to the interplay between IoT and control systems. In fact, regarding a control system as the one necessary to decide which sequence of actions will drive a system to the desired state, it is evident that IoT will improve the quality of such decisions, thanks to the pervasive availability of information about the system and its environment. Following this idea, the traditional role of centralised planning and control systems is substituted by the emerging behaviour of smart holons/agents because IoT allows to leave aside the necessity of centralised monitoring and action planning systems. Moreover, IoT will join systems at processes and field control level (edge tier) with supervisory, business and management systems (platform and enterprise tiers) with a seamless and homogeneous communication infrastructure and with plug and play capability. Such homogeneity makes it possible to combine disparate digital systems to take control actions at every instance of the value chain even remotely, taking into account every single aspect of the complete systems.

The integration and interoperability cluster acts as an abstract bus, which makes it possible to retrieve and share information for every actor in the CPPS. Every cluster is attached to this bus, so each one of their components can retrieve and share information as a basis for smart behaviours. The 
Fig. 2 Framework of conceptual enablers for CPPS

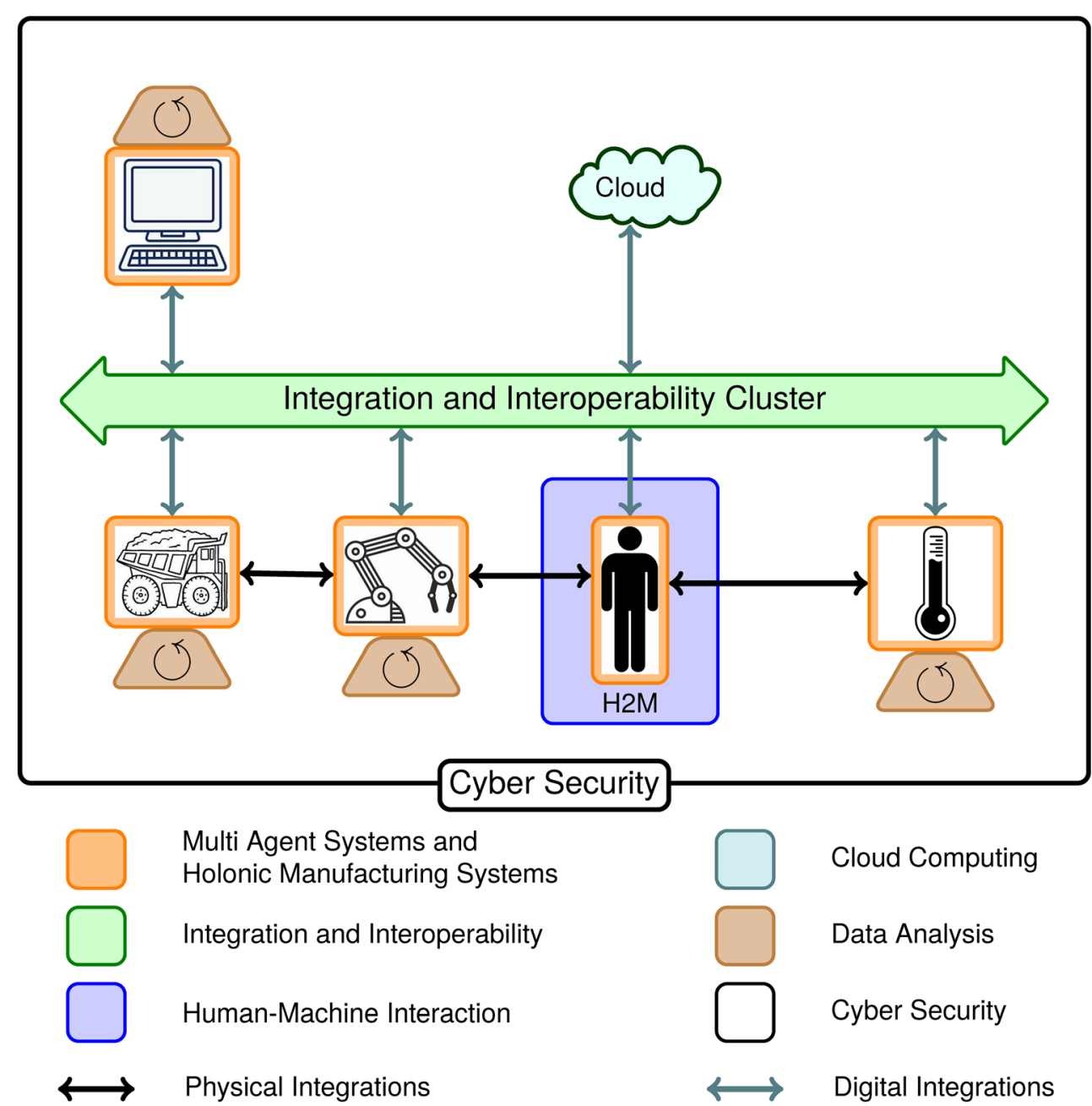

conceptual cluster of multi-agent systems and holonic manufacturing addresses the design and implementation of the features that the software layer of every node requires to achieve smart behaviour through the interaction which its peers. Humans are a very specific kind of holon, which need an interface layer to be integrated into the system. This is the layer below the conceptual cluster of human-machine interaction. The cloud appears as a special node that can partially contain a tier or specific function of another layer performed through the internet. At each digital instance, some kind of data processing is performed. Big data and demanding data processing is performed at the platform tier and enterprise tier. Meanwhile, at the edge tier, only real-time data processing is performed. Finally, the security layer is transversal to every other layer.

Autonomous agents are only capable to gather local information and have the ability to perform local actions. The IoT components of the CPPS will provide a communication channel which allows the formation of intelligence, thanks to global communication capabilities. So, such a generation of a smart production system is only possible, thanks to the interplay between control systems embodied into the MAS/HMS cluster and IoT. Meanwhile, MAS/HMS provide the theoretical background to implement smart behaviours through control systems, and IoT provides a communication channel with objects, which traditionally did not have communication capabilities. As an example, we could take a look to modern screwing tools. Thanks to IoT, i.e. endowing such simple tools with communication capabilities, it would be possible to monitor their state of charge and to regulate speed, torque or power consumption coordinating decisions in the whole production system.

We can think that interaction between MAS/HMS and IoT enables strategic-level decisions in comparison with the interaction between low-level control systems and IoT. Under such a perspective, the architecture of CPPS control systems is visualised in Fig. 3, where the interplay between control systems and IoT is represented. In that figure, a CPS represented by three layers interacts with a physical process and with the other nodes of the CPPS. Every CPS has an agent or a digital holon running in its software layer together with other processes the low-level control system. The agent acts as a supervisory control which chooses what control logic must be implemented to achieve the smart behaviour resulting from the 
Fig. 3 CPPS control system architecture

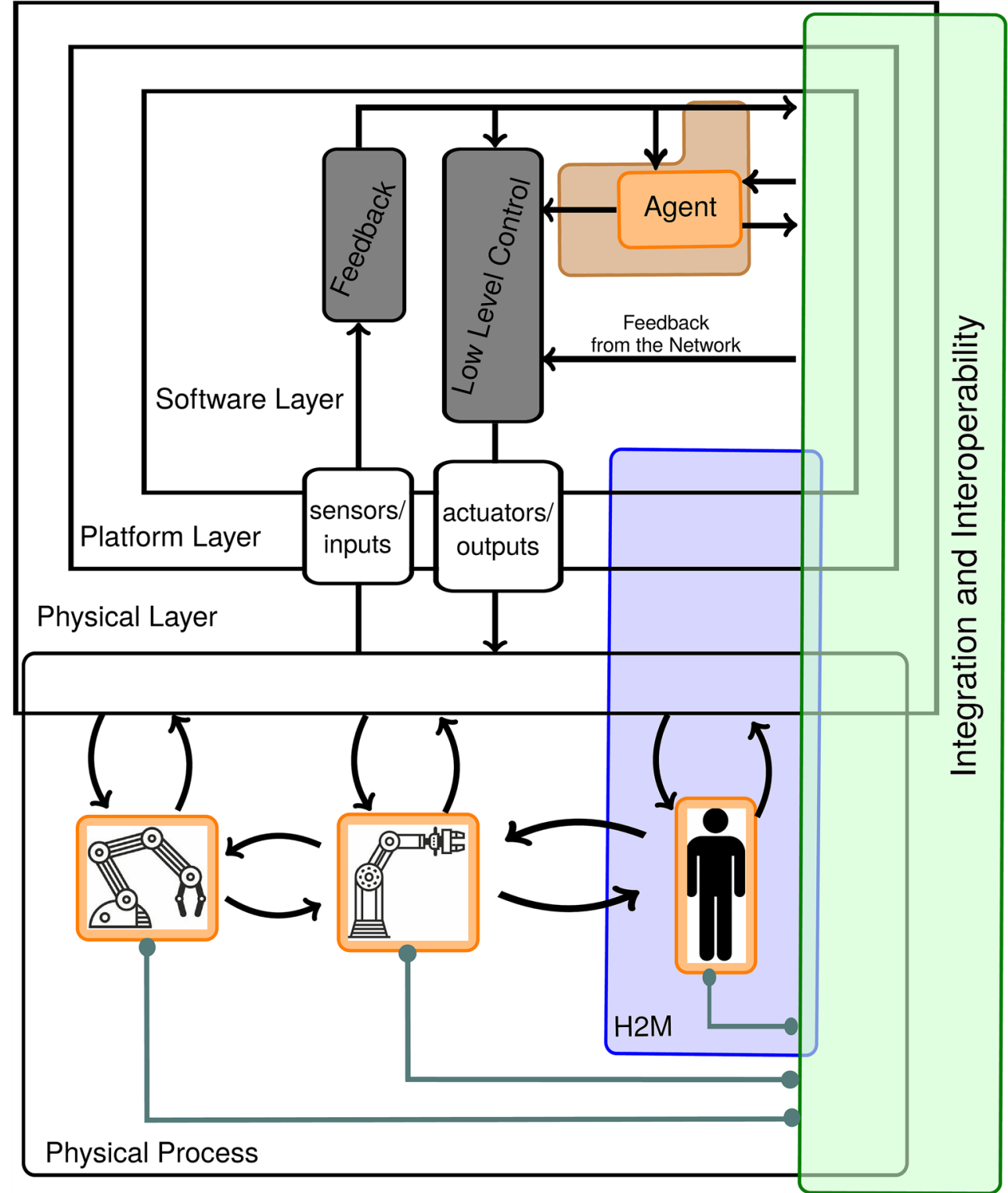

interaction with the other agents. On the one hand, the agent shares highly structured data in order to solve a high-level AI problem related to the coordination and orchestration of every CPS in agreement with their capabilities and the global objectives. On the other hand, the low-level control system addresses a more specific problem related to the physical part of the CPS and its model, and shares simple data structures. Following this order of ideas, we observe that the global control system of a CPS is composed of the agent and the lowlevel control system, sharing information with its peers in the CPPS network. We see the picture as a NCS implemented in an IoT, where the different conceptual clusters interact to achieve the objectives of the smart factory or CPPS. In fact, the bus of the integration and interoperability clusters penetrates the three layers of the CPS, reflecting the characteristics of the OSI model. The same happens with the human-machine interaction cluster because the issues involve any user interface (UI). The last two clusters (cloud computing and cyber security) are intersected to represent that the human-machine interaction may happen remotely. The data analysis cluster is overlapped with the MAS and HMS cluster and the integration and interoperability layer to denote that the functions of this cluster may be implemented locally by the agent or remotely.

The framework in Fig. 2 and the control system architecture of CPPS in Fig. 3 are intended to serve practitioners and researchers in order to visualise the enablers for the implementation of smart manufacturing control in modern CPPS in a clear and easy manner. Based on an extensive and detailed literature research, the framework contains the basic enablers that companies need for the implementation of modern and smart factories and also shows the relations and dependencies 
between these individual enablers. In addition to physical integrations, protected digital integrations for the connectivity of humans, machines and their environment are particularly important. The architecture illustrated in Fig. 3 provides practitioners and researchers with a guideline for connecting the individual elements of the CPPS through different layers, from the physical layer to the platform layer to the software layer, in order to implement smart manufacturing control in the sense of orchestrating the entire CPPS.

\section{Future directions of research in cyber-physical production systems}

CPPS is currently more of a desire than a reality. Several challenges must be addressed. In particular, we want to underline that the conceptual cluster of cyber security may represent a major obstacle in the development of CPPS. As commented before, the possibility of performing cross-domain attacks present a singular new challenge in which the complexity and unpredictability should not be underestimated. A new global approach to cyber security must integrate the dynamics of the physical system and the electronic platform to expand security at the hardware level as well as in the emergent dynamics. At the same time, traditional security systems must be expanded to the new requirements of Industry 4.0.

The conceptual cluster of MAS and HSM, the natural heterogeneity of the three layers composing a single CPS, involves an important level of complexity in determining how the layers will interact. Moreover, the behaviour of a single CPS will have an impact on the complexity, resulting in an emergent behaviour from the interaction between the individual agents that expose a relevant complexity characteristic in the non-linear system with high sensitivity to the boundary conditions. Since the interactions are difficult to predict, new models are necessary to understand and design smart CPPS, so that they will not behave in an unpredictable way.

The challenge in the integration and interoperability and cloud computing cluster will be to implement a NCS providing real-time communication to a body of heterogeneous CPS. On the one hand, the natural presence of disparate software layers behaves in a way that mandates the necessity of standard adoptions for assuring interoperability between the different devices. This fact imposes the challenge of developing new standards capable of meeting the requirements from different stakeholders. On the other hand, the evolution of fieldbus systems should address several issues regarding wireless communications, the implementation of safety-related networks and the integration of CPS with the internet. This will require new design principles to address the natural boundaries of this cluster with the MAS and HSM cluster and the resulting dynamic system.
In the cluster of data analytics, there are challenges related to the methodologies for handling, retrieving and storing very large amounts of data. The hardware for data storage may be very expensive even if cloud solutions are available. Regarding pattern recognition software solutions, they tend to have a high cost even if the beneficiary does opt for open source software. Even in such a case, the configuration and maintenance of such software may be done by specialists. Such solutions must become more accessible also for smalland medium-sized enterprises. On the other hand, there is a current need for developing computation models for recognising patterns in situations where heterogeneous data streams increase constantly, as in the case of data generated by mobile phones. Privacy is another challenge in the ulterior development of data analytics. In the case of big data, strict measures must be taken to respect the ethical and legal requirements of data collection to protect the privacy of the providers of the data.

In the cluster of human-machine interaction, different challenges have to be considered. Supporting workers in rare and not previously encountered situations requires adaptive UI that are capable to learn from their experience and predicting possible developments of a given situation. The possible implementation of AI techniques has opened up a completely new field in the development of UI. Multimodal UI are already an open field of research, where several possible implementations have not been addressed. In particular, the case of physical human robot interaction is a growing field of research.

\section{Conclusions}

We have identified and proposed six conceptual clusters of enablers to support the introduction and development of CPPS. These enablers were proposed by underlying the importance of feedback systems in CPS, which under aggregation behave in a way that demonstrates the necessity of integrating IoT with control systems. According to the findings of this research, the following conceptual enablers for smart manufacturing control systems were defined:

The (i) MAS and HMS cluster integrating the control systems of each CPS with the network of digital nodes inside the CPPS, transforming the traditional automation pyramid into a plateau of agents/holons that interact smartly to merge OT with IT. The cluster of (ii) integration and interoperability acts as an abstract bus, which connects every digital instance with (iii) cloud computing and expands the level of connectivity outside the boundaries of the CPPS. The cluster of (iv) data analysis collects the different techniques required to transform the raw data into meaningful information (big data into smart data), which is made available in every system in the communication bus. The cluster of (v) human-machine interaction 
appeared as an important enabler for integrating the humans inside the CPPS. Finally, the cluster of (vi) cyber security addresses the IT and OT merge where data security is a prerequisite to protect the CPPS from cyberattacks.

Finally, we developed a framework of conceptual enablers in CPPS as well as an architecture for the CPPS control systems. The proposed framework and the CPPS control system architecture underline the importance of control systems and reveal their interplay with IoT in a manufacturing system. As seen in the literature review, most of the scientific literature reports about individual and very specific problems in creating and implementing CPPS, but mostly, they do not report about the big picture of needed enablers for a successful implementation, which makes it difficult especially for practitioners to start the right measures and strategies.

The findings of our research should therefore not only serve as a basis for the further scientific development of CPPS, but also give practitioners an overview, which enablers should be considered in the implementation of smart factories of the future, and especially CPPS.

Funding information This research has received funding from the European Union's Horizon 2020 R\&I programme under the Marie Skłodowska-Curie grant agreement No 734713.

\section{Compliance with ethical standards}

Conflict of interest The authors declare that they have no conflict of interest.

Open Access This article is distributed under the terms of the Creative Commons Attribution 4.0 International License (http:// creativecommons.org/licenses/by/4.0/), which permits unrestricted use, distribution, and reproduction in any medium, provided you give appropriate credit to the original author(s) and the source, provide a link to the Creative Commons license, and indicate if changes were made.

\section{References}

1. Kagermann H, Wahlster W, Helbig J (2013) Securing the future of german manufacturing industry: recommendations for implementing the strategic intiative industrie 4.0. Final report of the Industrie 4.0 working group. Technical report, acatech

2. Gilchrist A (2016) Industry 4.0: the industrial internet of things. Apress, New York

3. Lee EA (2008) Cyber-physical systems: design challenges. In: 11th IEEE International Symposium on Object and ComponentOriented Real-Time Distributed Computing (ISORC), Orlando, FL, pp 363-369

4. Gupta RA, Chow M-Y (2010) Networked control system: overview and research trends. IEEE Trans Ind Electron 57(7):25272535. https://doi.org/10.1109/TIE.2009.2035462

5. Monostori L, Kádár B, Bauernhansl T, Kondoh S, Kumara S, Reinhart G, Sauer O, Schuh G, Sihn S, Ueda K (2016) Cyberphysical systems in manufacturing. CIRP Ann Manuf Techn 65(2):621-641. https://doi.org/10.1016/j.cirp.2016.06.005
6. Trappey ACJ, Trappey CV, Govindarajan UH, Sun JJ, Chuang AC (2016) A review of technology standards and patent portfolios for enabling cyber-physical systems in advanced manufacturing. IEEE Access 4:7356-7382. https://doi.org/10.1109/ACCESS. 2016.2619360

7. Oesterreich TD, Teuteberg F (2016) Understanding the implications of digitisation and automation in the context of industry 4.0: a triangulation approach and elements of a research agenda for the construction industry. Comput Ind 83:121-139. https://doi.org/10. 1016/j.compind.2016.09.006

8. Kang HS, Lee JY, Choi S, Kim H, Park JH, Son JY, Kim BH, Noh SD (2016) Smart manufacturing: past research, present findings, and future directions. Int J Precis Eng Man 3(1):111-128. https:// doi.org/10.1007/s40684-016-0015-5

9. Monostori L (2014) Cyber-physical production systems: roots, expectations and challenges. Procedia CIRP 17:9-13. https://doi. org/10.1016/j.procir.2014.03.115

10. Wang L, Törngren M, Onori M (2015) Current status and advancement of cyber-physical systems in manufacturing. J Manuf Syst 37:517-527. https://doi.org/10.1016/j.jmsy.2015.04.008

11. Leitão P, Colombo AW, Karnouskos S (2016) Industrial automation based on cyber-physical systems technologies: prototype implementations and challenges. Comput Ind 81:11-25. https:// doi.org/10.1016/j.compind.2015.08.004

12. Thoben K-D, Wiesner S, Wuest T (2017) Industrie 4.0 and smart manufacturing - a review of research issues and application examples. Int J Autom Technol 11(1):4-19. https://doi.org/10. 20965/ijat.2017.p0004

13. Sztipanovits J, Koutsoukos X, Karsai G, Kottenstette N, Antsaklis P, Gupta V, Goodwine B, BarasJ WS (2012) Toward a science of cyber-physical system integration. Proc IEEE 100(1):29-44. https://doi.org/10.1109/JPROC.2011.2161529

14. Jick TD (1979) Mixing qualitative and quantitative methods: triangulation in action. Adm Sci Q 24(4):602-611. https://doi.org/ $10.2307 / 2392366$

15. Lee J, Bagheri B, Kao H-A (2015) A cyber-physical systems architecture for industry 4.0-based manufacturing systems. Manuf Lett 3: 18-23. https://doi.org/10.1016/j.mfglet.2014.12.001

16. Cengarle V, Törngren M, Bensalem S, McDermid J, SangiovanniVincentelli A, Passerone R (2013) Structuring of CPS domain: characteristics, trends, challenges and opportunities associated with CPS. Technical report

17. Thompson H, Paulen R, Reniers M, Sonntag C, Engell S (2015) Analysis of the state-of-the-art and future challenges in cyberphysical systems of systems. Technical report, CPSoS

18. Booth A, Sutton A, Papaioannou D (2016) Systematic approaches to a successful literature review. Sage, Newcastle upon Tyne

19. Tranfield D, Denyer D, Smart P (2003) Towards a methodology for developing evidence-informed management knowledge by means of systematic review. Br J Manag 14(3):207-222. https:// doi.org/10.1111/1467-8551.00375

20. Petticrew M, Roberts H (2008) Systematic reviews in the social sciences: a practical guide. Wiley, Hoboken

21. Denyer D, Tranfield D (2009) Producing a systematic review. In: Buchanan DA, Bryman A (eds) The Sage handbook of organizational research methods. Sage, Thousand Oaks, CA, pp 671-689

22. Durach CF, Kembro J, Wieland A (2017) A new paradigm for systematic literature reviews in supply chain management. J Supply Chain Manag 53(4):67-85. https://doi.org/10.1111/jscm.12145

23. Maxwell W, Muckstadt JA, Thomas LJ, Vander Eecken J (1983) A modeling framework for planning and control of production in discrete parts manufacturing and assembly systems. Interfaces 13(6):92-104. https://doi.org/10.1287/inte.13.6.92

24. Mathews JA (1995) Holonic foundations of intelligent manufacturing systems. In: 5th IFAC symposium on automated 
system based on human skill, joint Design of Technology and Organisation, Berlin, pp 25-28

25. Weiss G (1999) Multiagent systems: a modern approach to distributed artificial intelligence. MIT press, Cambridge

26. Wooldridge M, Jennings NR (1995) Intelligent agents: theory and practice. Knowl Eng Rev 10(2):115-152. https://doi.org/10.1017/ S0269888900008122

27. Müller R, Vette M, Hörauf L, Speicher C, Jatti K (2016) Concept and implementation of an agent-based control architecture for a cyber-physical assembly system. MATEC Web of Conferences 42:04003. https://doi.org/10.1051/matecconf/20164204003

28. Vogel-Heuser B, Lee J, Leitão P (2015) Agents enabling cyberphysical production systems. at-Automatisierungstechnik 63(10): 777-789. https://doi.org/10.1515/auto-2014-1153

29. Ji X, He G, Xu J, Guo Y (2016) Study on the mode of intelligent chemical industry based on cyber-physical system and its implementation. Adv Eng Softw 99:18-26. https://doi.org/10.1016/j. advengsoft.2016.04.010

30. Leitao P, Karnouskos S, Ribeiro L, Lee J, Strasser T, Colombo AW (2016) Smart agents in industrial cyber-physical systems. Proc IEEE 104(5):1086-1101. https://doi.org/10.1109/JPROC. 2016.2521931

31. Penas O, Plateaux R, Patalano S, Hammadi M (2016) Multi-scale approach from mechatronic to cyber-physical systems for the design of manufacturing systems. Comput Ind 86:52-69. https://doi. org/10.1016/j.compind.2016.12.001

32. Ilsen R, Meissner H, Aurich JC (2017) Optimizing energy consumption in a decentralized manufacturing system. J Comput Inf Sci Eng 17(2):021006. https://doi.org/10.1115/1.4034585

33. Koestler A (1968) The ghost in the machine. Macmillan, New York

34. Tharumarajah A (1996) Comparison of the bionic, fractal and holonic manufacturing system concepts. Int J Comput Integ M 9(3):217-226. https://doi.org/10.1080/095119296131670

35. McFarlane DC (1995) Holonic manufacturing systems in continuous processing: concepts and control requirements. In: Proceedings of ASI 95, pp. 273-282

36. Bussmann S (1998) An agent-oriented architecture for holonic manufacturing control. In: Proceedings of first international workshop on IMS, Lausanne, Switzerland, pp. 1-12

37. Wang L, Haghighi A (2016) Combined strength of holons, agents and function blocks in cyber-physical systems. J Manuf Syst 40: 25-34. https://doi.org/10.1016/j.jmsy.2016.05.002

38. Pujo P, Ounnar F, Power D, Khader S (2016) Wireless Holon network for job shop isoarchic control. Comput Ind 83:12-27. https://doi.org/10.1016/j.compind.2016.08.005

39. Quintanilla FG, Cardin O, L'Anton A, Castagna P (2016) Implementation framework for cloud-based holonic control of cyber-physical production systems. In: 14th International Conference on Industrial Informatics (INDIN), pp. 316-321

40. ISO (2002) ISO 19439, CIM system architecture-framework for enterprise modelling. Technical report

41. Rojas RA, Rauch E, Vidoni R, Matt DT (2017) Enabling connectivity of cyber-physical production systems: a conceptual framework. Procedia Manufacturing 11:822-829. https://doi.org/10. 1016/j.promfg.2017.07.184

42. Zimmermann H (1980) Osi reference model-the iso model of architecture for open systems interconnection. IEEE Trans Commun 28(4):425-432. https://doi.org/10.1109/TCOM.1980.1094702

43. Garcá MV, Irisarri E, Pérez F, Estévez E, Marcos M (2016) Opc-ua communications integration using a cpps architecture. Ecuador Technical Chapters Meeting (ETCM) 1:1-6. https://doi.org/10. 1109/ETCM.2016.7750838

44. Astarloa A, Bidarte U, Jiménez J, Zuloaga A, Lázaro J (2016) Intelligent gateway for industry 4.0-compliant production. In: Industrial electronics society, IECON 2016-42nd annual conference of the IEEE, pp 4902-4907. https://doi.org/10.1109/ IECON.2016.7793890

45. Astarloa A, Moreira N, Lázaro J, Urbina M, Garcia A (2015) 1588-aware high-availability cyber-physical production systems. In: IEEE International Symposium on Precision Clock Synchronization for Measurement, Control, and Communication (ISPCS), Bejing, China, pp 25-30. https://doi.org/10.1109/ISPCS. 2015.7324675

46. Cammin C, Krush D, Heynicke R, Scholl G, Schulze C, Thiede S, Herrmann C (2016) Coexisting wireless sensor networks in cyberphysical production systems. In: 21 st international conference on emerging technologies and factory automation (ETFA), Berlin, Germany, pp 1-4. https://doi.org/10.1109/ETFA.2016.7733593

47. Puhm A, Mahmood A, Bigler T, Kerö N (2016) Synchronizing an ieee 1588 slave clock over both paths of a redundant ethernet system. In: International Symposium on Precision Clock Synchronization for Measurement, Control, and Communication (ISPCS), Stockholm, Sweden, pp 1-6. https://doi.org/10.1109/ ISPCS.2016.7579507

48. Dai W, Huang W, Vyatkin V (2016) Enabling plug-and-play software components in industrial cyber-physical systems by adopting service-oriented architecture paradigm. In: IECON 2016-42nd annual conference of the industrial electronics society, Florence, Italy, pp 5253-5258. https://doi.org/10.1109/IECON.2016. 7793834

49. Schleipen M, Lüder A, Sauer O, Flatt H, Jasperneite J (2015) Requirements and concept for plug-and-work. atAutomatisierungstechnik 63(10):801-820. https://doi.org/10. 1515/auto-2015-0015

50. Furmans K, Schönung F, Gue KR (2010) Plug and work material handling systems. In Progress in Material Handling Research, Milwaukee, WI, pp 32-142

51. Schmidt N, Luder A, Rosendahl R, Ryashentseva D, Foehr M, Vollmar J (2015) For a better understanding of integration. In: IECON 2015-41st annual conference of the Industrial Electronics Society, Yokohama, Japan, pp. 002717-002722. https://doi.org/10.1109/IECON.2015.7392512

52. Schmidt N, Luder A, Rosendahl R, Ryashentseva D, Foehr M, Vollmar J (2015) Surveying integration approaches for relevance in cyber-physical production systems. In: 2015 IEEE 20th conference on emerging technologies \& factory automation (ETFA), Luxembourg, Luxembourg, pp 1-8. https://doi.org/10.1109/ ETFA.2015.7301518

53. Saldivar AAF, Li Y, Chen W, Zhan Z, Zhang J, Chen LY (2015) Industry 4.0 with cyber-physical integration: a design and manufacture perspective. In: 2015 21st international conference on automation and computing (icac), Glasgow, UK, pp 1-6. https://doi. org/10.1109/IConAC.2015.7313954

54. Vernadat FB (2007) Interoperable enterprise systems: principles, concepts, and methods. Annu Rev Control 31(1):137-145. https:// doi.org/10.1016/j.arcontrol.2007.03.004

55. Yoon SC, Suh S-H (2016) Manufacturing information bus from the perspective of cyber-physical manufacturing system (cpms). IFAC-PapersOnLine 49(31):103-108. https://doi.org/10.1016/j. ifacol.2016.12.169

56. MESA (2008) Soa in manufacturing guidebook. Technical report. MESA International, IBM Corporation and Capgemini. ftp:// public.dhe.ibm.com/software/plm/pdif/MESA_ SOAinManufacturingGuidebook.pdf. Accessed 26 June 2018

57. Morariu C, Morariu O, Borangiu T, Raileanu S (2013) Manufacturing service bus integration model for highly flexible and scalable manufacturing systems. In: Borangiu T, Thomas A, Trentesaux D (eds) Service orientation in Holonic and multi agent manufacturing and robotics. Springer, Berlin Heidelberg, pp 1940

58. Chappell D (2004) Enterprise Service bus. O’Reilly 
59. Krueger V, Chazoule A, Crosby M, Lasnier A, Pedersen MR, Rovida F, Nalpantidis L, Petrick R, Toscano C, Veiga G (2016) A vertical and cyber-physical integration of cognitive robots in manufacturing. Proc IEEE 104(5):1114-1127. https://doi.org/10. 1109/JPROC.2016.2521731

60. Arrais R, Oliveira M, Toscano C, Veiga G (2017) A mobile robot based sensing approach for assessing spatial inconsistencies of a logistic system. J Manuf Syst 43:129-138. https://doi.org/10. 1016/j.jmsy.2017.02.016

61. Neubauer M, Krenn F, Majoe D, Stary C (2017) Subjectorientation as design language for integration across organisational control layers. Int J Prod Res 55(13):3644-3656. https://doi.org/10.1080/00207543.2016.1198058

62. Tao F, Cheng J, Cheng Y, Gu S, Zheng T, Yang H (2017) Sdmsim: a manufacturing service supply-demand matching simulator under cloud environment. Robot Cim Int Manuf 45:34-46. https:// doi.org/10.1016/j.rcim.2016.07.001

63. Weichhart G, Guédria W, Naudet Y (2016) Supporting interoperability in complex adaptive enterprise systems: a domain specific language approach. Data Knowl Eng 105:90-106. https://doi.org/ 10.1016/j.datak.2016.04.001

64. Sauer O (2014) Developments and trends in shopfloor-related ict systems. In: International Conference on Industrial Engineering and Engineering Management (IEEM), Bandar Sunway, Malaysia, pp 1352-1356. https://doi.org/10.1109/IEEM.2014. 7058859

65. Lin SW, Mellor S, Miller B, Durand J, Crawford M, Lambree R (2015) Industrial internet reference architecture. Technical report, Industrial Internet Consortium https://www.iiconsortium.org/ IIRA-1-7-ajs.pdf. Accessed 13 May 2018

66. Papazoglou MP, Traverso P, Dustdar S, Leymann F (2007) Service-oriented computing: state of the art and research challenges. Computer 40(11):38-45. https://doi.org/10.1109/MC. 2007.400

67. Georgakopoulos D, Papazoglou M (2009) Service-oriented computing. MIT press, Cambridge

68. Puttonen J, Lobov A, Cavia Soto MA, Martinez Lastra JL (2015) Planning-based semantic web service composition in factory automation. Adv Eng Inform 29(4):1041-1054. https://doi.org/10. 1016/j.aei.2015.08.002

69. Quintanilla FG, Cardin O, L'Anton A, Castagna P (2016) Virtual commissioning-based development and implementation of a service-oriented holonic control for retrofit manufacturing systems. In: Borangiu T, Trentesaux D, Thomas A, McFarlane D (eds) Service orientation in Holonic and multi-agent manufacturing. Springer, Cham, pp 233-242

70. Morgan J, O’Donnell GE (2017) Enabling a ubiquitous and cloud manufacturing foundation with field-level service-oriented architecture. Int J Comput Integ M 30(4-5):442-458. https://doi.org/ 10.1080/0951192X.2015.1032355

71. Dai W, Huang W, Vyatkin V (2016) Knowledge-driven service orchestration engine for flexible information acquisition in industrial cyber-physical systems. In: 25th International Symposium on Industrial Electronics (ISIE), Santa Clara, CA, pp 1055-1060. https://doi.org/10.1109/ISIE.2016.7745038

72. Hoffmann M, Thomas P, Schütz D, Vogel-Heuser B, Meisen T, Jeschke S (2016) Semantic integration of multi-agent systems using an opc ua information modeling approach. In: 14th International Conference on Industrial Informatics (INDIN), Poitiers, France, pp 744-747. https://doi.org/10.1109/INDIN. 2016.7819258

73. Ploennigs J, Clement J, Wollschlaeger B, Kabitzsch K (2016) Semantic models for physical processes in cps at the example of occupant thermal comfort. In: 25th International Symposium on Industrial Electronics (ISIE), Santa Clara, CA, pp 1061-1066. https://doi.org/10.1109/ISIE.2016.7745039
74. Thramboulidi K, Christoulakis F (2016) UML4IoT - A UML profile to exploit IoT in cyber-physical manufacturing systems. Comput Ind 82:259-272. https://doi.org/10.1016/j.compind. 2016.05.010

75. Hehenberger P, Vogel-Heuser B, Bradley D, Eynard B, Tomiyama $\mathrm{T}$, Achiche S (2016) Design, modelling, simulation and integration of cyber-physical systems: methods and applications. Comput Ind 82:273-289. https://doi.org/10.1016/j.compind.2016.05.006

76. Galaske N, Tantik E, Anderl R (2015) Discrete-event simulation software for modeling flexibility-driven manufacturing processes. In: ASME 2015 international design engineering technical conferences and computers and information in engineering conference, Boston, MA, pp V004T05A015-V004T05A015. https://doi.org/ 10.1115/DETC2015-47411

77. Moon S, Kang S, Jeon J, Chun I (2016) Simulation modeling of sewing process for evaluation of production schedule in smart factory. In: International Conference on Industrial Engineering, Management Science and Application (ICIMSA), Jeju, South Korea, pp 1-3. https://doi.org/10.1109/ICIMSA.2016.7504033

78. Weckenmann A, Hartmann W (2015) A model-and simulationbased approach for tolerancing and verifying the functional capability of micro/nano-structured workpieces. Measurement 76:7079. https://doi.org/10.1016/j.measurement.2015.08.010

79. Schmitt RH, Peterek M, Morse E, Knapp W, Galetto M, Härtig F, Goch G, Hughes B, Forbes A, Estler WT (2016) Advances in large-scale metrology-review and future trends. CIRP Ann Manuf Technol 65(2):643-665. https://doi.org/10.1016/j,cirp. 2016.05.002

80. Geiger F, Reinhart G (2016) Knowledge-based machine scheduling under consideration of uncertainties in master data. Prod Eng 10(2):197-207. https://doi.org/10.1007/s11740-015-0652-5

81. Grundstein S, Freitag M, Scholz-Reiter B (2017) A new method for autonomous control of complex job shops-integrating order release, sequencing and capacity control to meet due dates. $\mathrm{J}$ Manuf Syst 42:11-28, 2017. https://doi.org/10.1016/j.jmsy.2016. 10.006

82. Freitag M, Becker T, Duffie NA (2015) Dynamics of resource sharing in production networks. CIRP Ann Manuf Technol 64(1):435-438. https://doi.org/10.1016/j.cirp.2015.04.124

83. Kang S, Jeon J, Kim H-S, Chun I (2016) Cps-based fault-tolerance method for smart factories. at-Automatisierungstechnik 64(9): 750-757. https://doi.org/10.1515/auto-2016-0065

84. Maier A (2014) Online passive learning of timed automata for cyber-physical production systems. In: 12th IEEE International Conference on Industrial Informatics (INDIN), Port Alegre, Brasil, pp 60-66. https://doi.org/10.1109/INDIN.2014.6945484

85. Maier A, Niggemann O, Eickmeyer J (2015) On the learning of timing behavior for anomaly detection in cyber-physical production systems. In DX@ Safeprocess, pp 217-224

86. Niggemann O, Frey C (2015) Data-driven anomaly detection in cyber-physical production systems. at-Automatisierungstechnik 63(10):821-832. https://doi.org/10.1515/auto-2015-0060

87. Mourtzis D, Vlachou E, Milas N (2016) Industrial big data as a result of iot adoption in manufacturing. Procedia CIRP 55:290 295. https://doi.org/10.1016/j.procir.2016.07.038

88. Windmann S, Maier A, Niggemann O, Frey C, Bernardi A, Gu Y, Pfrommer H, Steckel T, Krüger M, Kraus R (2015) Big data analysis of manufacturing processes. J Phys Conf Ser 659:012055. https://doi.org/10.1088/1742-6596/659/1/012055

89. Gronau N, Grum M, Bender B (2016) Determining the optimal level of autonomy in cyber-physical production systems. In: 14th International Conference on Industrial Informatics (INDIN), Poitiers, France, pp 1293-1299. https://doi.org/10.1109/INDIN. 2016.7819367 
90. Liu Y, Xu X (2017) Industry 4.0 and cloud manufacturing: a comparative analysis. J Manuf Sci Eng 139(3):034701. https:// doi.org/10.1115/1.4034667

91. Marini A, Bianchini D (2016) Big data as a service for monitoring cyber-physical production systems. ECMS:579-586. https://doi. org/10.7148/2016-0579

92. Tao F, Zhang L, Venkatesh VC, Luo Y, Cheng Y (2011) Cloud manufacturing: a computing and service-oriented manufacturing model. J Eng Manuf 225(10):1969-1976. https://doi.org/10.1177/ 0954405411405575

93. Vaquero LM, Rodero-Merino L, Caceres J, Lindner M (2008) A break in the clouds: towards a cloud definition. ACM SIGCOMM Comput Commun Rev 39(1):50-55. https://doi.org/10.1145/ 1496091.1496100

94. Xu X (2012) From cloud computing to cloud manufacturing. Robot Cim Int Manuf 28(1):75-86. https://doi.org/10.1016/j. rcim.2011.07.002

95. Wang L (2017) An overview of internet-enabled cloud-based cyber manufacturing. Trans Inst Meas Control 39(4):388-397. https://doi.org/10.1177/0142331216687817

96. Weinberger M, Bilgeri D, Fleisch E (2016) Iot business models in an industrial context. at-Automatisierungstechnik 64(9):699-706. https://doi.org/10.1515/auto-2016-0054

97. Zhou K, Liu T, Liang L (2016) From cyber-physical systems to industry 4.0: make future manufacturing become possible. Int J Manuf Res 11(2):167-188. https://doi.org/10.1504/IJMR.2016. 078251

98. Zhou K, Liu T, Zhou L (2015) Industry 4.0: towards future industrial opportunities and challenges. In: 12th International Conference on Fuzzy Systems and Knowledge Discovery (FSKD), Zhangjiajie, China, pp 2147-2152. https://doi.org/10. 1109/FSKD.2015.7382284

99. Skarlat O, Borkowski M, Schulte S (2016) Towards a methodology and instrumentation toolset for cloud manufacturing. In: 1st international workshop on cyber-physical production Systems (CPPS), Vienna, Austria, pp 1-4. https://doi.org/10.1109/CPPS. 2016.7483920

100. Schlechtendahl J, Keinert M, Kretschmer F, Lechler A, Verl A (2015) Making existing production systems industry 4.0-ready. Prod Eng 9(1):143-148. https://doi.org/10.1007/s11740-0140586-3

101. Helo P, Suorsa M, Hao Y, Anussornnitisarn P (2014) Toward a cloud-based manufacturing execution system for distributed manufacturing. Comput Ind 65(4):646-656. https://doi.org/10. 1016/j.compind.2014.01.015

102. Wang S, Wan J, Imran M, Li D, Zhang C (2016) Cloud-based smart manufacturing for personalized candy packing application. J Supercomput 74:1-19. https://doi.org/10.1007/s11227-016$1879-4$

103. Makarov O, Langmann R, Nesterenko S, Frank B (2014) Problems of the time deterministic in applications for process control from the cloud. Int J Online Eng 10(4):70-73. https:// doi.org/10.3991/ijoe.v10i4.383

104. Verl A, Lechler A, Schlechtendahl J (2012) Glocalized cyberphysical production systems. Prod Eng 6(6):643-649. https:// doi.org/10.1007/s11740-012-0418-2

105. Caggiano A, Segreto T, Teti R (2016) Cloud manufacturing framework for smart monitoring of machining. Procedia CIRP 55:248253. https://doi.org/10.1016/j.procir.2016.08.049

106. Zolotová I, Bundzel M, Lojka T (2015) Industry IoT gateway for cloud connectivity. In: Umeda S, Nakano M, Mizuyama H, Hibino $\mathrm{H}$, Kiritsis D, von Cieminski G (eds) Advances in production management systems: innovative production management towards sustainable growth. APMS 2015. IFIP Advances in Information and Communication Technology, vol 460. Springer, Cham, pp. 59-66
107. Yen CT, Liu YC, Lin C-C, Kao C-C, Wang W-B, Hsu Y-R (2014) Advanced manufacturing solution to industry 4.0 trend through sensing network and cloud computing technologies. In: International Conference on Automation Science and Engineering (CASE), Tapai, Taiwan, pp 1150-1152. https://doi. org/10.1109/CoASE.2014.6899471

108. Ferreira F, Faria J, Azevedo A, Marques AL (2016) Product lifecycle management enabled by industry 4.0 technology. In: Goh YM, Case K (eds.) Adv Transdisciplinary Eng, Volume 3, pp. 349-354. https://doi.org/10.3233/978-1-61499-668-2-349

109. Makarov O, Langmann R, Frank B (2014) Signal time deterministic for process control applications from the cloud. In: 11th International Conference on Remote Engineering and Virtual Instrumentation (REV), Porto, Portugal, pp 440-443. https://doi. org/10.1109/REV.2014.6784242

110. Mejás A, Herrera RS, Márquez MA, Calderón AJ, González I, Andújar JM (2017) Easy handling of sensors and actuators over tcp/ip networks by open source hardware/software. Sensors 17(1): 94. https://doi.org/10.3390/s17010094

111. Ansari F, Seidenberg U (2016) A portfolio for optimal collaboration of human and cyber-physical production systems in problemsolving. 13th international conference on cognition and exploratory learning in digital age (CELDA), pp 311-314

112. Becker T, Stern H (2016) Future trends in human work area design for cyber-physical production systems. Procedia CIRP 57:404 409. https://doi.org/10.1016/j.procir.2016.11.070

113. Fantini P, Tavola G, Taisch M, Barbosa J, Leitao P, Liu Y, Sayed MS, Lohse N (2016) Exploring the integration of the human as a flexibility factor in cps enabled manufacturing environments: methodology and results. In: 42nd Annual Conference of Industrial Electronics Society (IECON), Florence, Italy, pp 5711-5716. https://doi.org/10.1109/IECON.2016.7793579

114. Jiang P, Leng J, Ding K, Gu P, Koren Y (2016) Social manufacturing as a sustainable paradigm for mass individualization. Proc Inst Mech Eng B J Eng Manuf 230(10):1961-1968. https://doi.org/10. 1177/0954405416666903

115. Pirvu B-C, Zamfirescu C-B, Gorecky D (2016) Engineering insights from an anthropocentric cyber-physical system: a case study for an assembly station. Mechatronics 34:147-159. https://doi.org/ 10.1016/j.mechatronics.2015.08.010

116. Hold P, Ranz F, Sihn W, Hummel V (2016) Planning operator support in cyber-physical assembly systems. IFACPapersOnLine 49(32):60-65. https://doi.org/10.1016/j.ifacol. 2016.12.190

117. Gorecky D, Schmitt M, Loskyll M, Zühlke D (2014) Humanmachine-interaction in the industry 4.0 era. In: 12 th IEEE International Conference on Industrial Informatics (INDIN), Porto Alegre, Brasil, pp 289-294. https://doi.org/10.1109/ INDIN.2014.6945523

118. Oviatt S, Cohen P (2000) Perceptual user interfaces: multimodal interfaces that process what comes naturally. Commun ACM 43(3):45-53. https://doi.org/10.1145/330534.330538

119. OShaughnessy D (2008) Ínvited paper: automatic speech recognition: history, methods and challenges. Pattern Recogn 41(10): 2965-2979. https://doi.org/10.1016/j.patcog.2008.05.008

120. Lotterbach S, Peissner M (2005) Voice user interfaces in industrial environments. GI Jahrestagung, pp. 592-596. https://subs.emis. de/LNI/Proceedings/Proceedings68/GI-Proceedings.68-121.pdf. Accessed 20 April 2018

121. Goose S, Sudarsky S, Zhang X, Navab N (2003) Speech-enabled augmented reality supporting mobile industrial maintenance. IEEE Pervasive Comput 2(1):65-70. https://doi.org/10.1109/ MPRV.2003.1186727

122. Inc. Lucas Systems (2018) Mobile work beyond voice picking. https://www.lucasware.com/jennifer-voice-picking/. Accessed 20 March 2018 
123. Posada J, Toro C, Barandiaran I, Oyarzun D, Stricker D, de Amicis R, Pinto EB, Eisert P, Döllner J, Vallarino I (2015) Visual computing as a key enabling technology for industrie 4.0 and industrial internet. IEEE Comput Graph Appl 35(2):26-40. https://doi.org/ 10.1109/MCG.2015.45

124. Sansoni G, Trebeschi M, Docchio F (2009) State-of-the-art and applications of $3 \mathrm{~d}$ imaging sensors in industry, cultural heritage, medicine, and criminal investigation. Sensors 9(1):568-601. https://doi.org/10.3390/s90100568

125. Triesch J, von der Malsburg C (1998) Robotic gesture recognition. Springer, Berlin Heidelberg, pp 233-244

126. Brethes L, Menezes P, Lerasle F, Hayet J (2004) Face tracking and hand gesture recognition for human-robot interaction. In: International conference on robotics and automation (ICRA'04), volume 2, New Orleans, LA, pp 1901-1906. https://doi.org/10. 1109/ROBOT.2004.1308101

127. Mitra S, Acharya T (2007) Gesture recognition: a survey. IEEE Trans Syst Man Cybern Part C Appl Rev 37(3):311-324. https:// doi.org/10.1109/TSMCC.2007.893280

128. Heimonen T, Hakulinen J, Turunen M, Jokinen JPP, Keskinen T, Raisamo R (2013) Designing gesture-based control for factory automation. In: Kotzé P, Marsden G, Lindgaard G, Wesson J, Winckler M (eds) Human-computer interaction - INTERACT 2013. Lecture notes in computer science, vol 8118. Springer, Berlin

129. Craig AB (2013) Understanding augmented reality: concepts and applications. Morgan Kaufmann, Newnes

130. Raskar R, Welch G, Fuchs H (1998) Spatially augmented reality. In: First IEEE workshop on augmented reality, pp 11-20

131. Heutger M, Kückelhaus M (2014) Augmented reality in logistics. Technical report, DHL. http://www.dhl.com/content/dam/ downloads/g0/about_us/logistics_insights/csi_augmented reality_report_290414.pdf. Accessed 23 April 2018

132. Olwal A, Gustafsson J, Lindfors C (2008) Spatial augmented reality on industrial cnc-machines. In: electronic imaging 2008, International Society for Optics and Photonics, San Jose, CA, pp 680409-680409. https://doi.org/10.1117/12.760960

133. Guerin KR, Lea C, Paxton C, Hager GD (2015) A framework for end-user instruction of a robot assistant for manufacturing. In: International Conference on Robotics and Automation (ICRA), Seattle, WA, pp 6167-6174. https://doi.org/10.1109/ICRA.2015. 7140065

134. Haddadin S, Haddadin S, Khoury A, Rokahr T, Parusel S, Burgkart R, Bicchi A, Albu-Schäffer A (2012) On making robots understand safety: embedding injury knowledge into control. Int J Robot Res 31(13):1578-1602. https://doi.org/10.1177/ 0278364912462256

135. Cherubini A, Passama R, Crosnier A, Lasnier A, Fraisse P (2016) Collaborative manufacturing with physical human-robot interaction. Robot Cim Int Manuf 40:1-13. https://doi.org/10.1016/j. rcim.2015.12.007

136. Bergamasco M, Herr H (2016) Human-robot augmentation. In: Siciliano B, Khatib O (eds) Springer handbook of robotics, chapter 70, pp. 1875-1906. Springer, Berlin Heidelberg. https://doi.org/ 10.1007/978-3-319-32552-1 70

137. Taylor R, Jensen P, Whitcomb L, Barnes A, Kumar R, Stoianovici D, Gupta P, Wang ZX, Dejuan E, Kavoussi L (1999) A steadyhand robotic system for microsurgical augmentation. Int J Robot Res 18(12):1201-1210.https://doi.org/10.1177/ 02783649922067807

138. Shields BL, Main JA, Peterson SW, Strauss AM (1997) An anthropomorphic hand exoskeleton to prevent astronaut hand fatigue during extravehicular activities. IEEE Trans Syst Man Cybern A Syst Hum 27(5):668-673. https://doi.org/10.1109/3468.618265

139. Bogue R (2015) Robotic exoskeletons: a review of recent progress. Ind Robot 42(1):5-10. https://doi.org/10.1108/IR-08-20140379

140. Cardenas A, Amin S, Sinopoli B, Giani A, Perrig A, Sastry S (2009) Challenges for securing cyber-physical systems. In: Workshop on future directions in cyber-physical systems security, p. 5

141. Choo KKR (2011) The cyber threat landscape: challenges and future research directions. Comput Secur 30(8):719-731. https:// doi.org/10.1016/j.cose.2011.08.004

142. Wu G, Sun J, Chen J (2016) A survey on the security of cyberphysical systems. Control Theory Technol 14(1):2-10. https://doi. org/10.1007/s11768-016-5123-9

143. Ullrich J, Voyiatzis AG, Weippl ER (2016) Secure cyber-physical production systems: solid steps towards realization. In: 1st international workshop on cyber-physical production Systems (CPPS), Vienna, Austria, pp 1-4. https://doi.org/10.1109/CPPS.2016. 7483921

144. Chhetri SR, Wan J, and Al Faruque MA (2017) Cross-domain security of cyber-physical systems. In: 22nd Asia and South Pacific design automation conference (ASP-DAC), Chiba, Japan, pp 200-205. https://doi.org/10.1109/ASPDAC.2017. 7858320

145. Lee RM, Assante MJ, Conway T (2014) German steel mill cyber attack. Industrial control Systems 30. https://ics.sans.org/media/ ICS-CPPE-case-Study-2-German-Steelworks_Facility.pdf. Accessed 13 June 2018

146. Falliere N, Murchu LO, Chien E (2011) W32. stuxnet dossier. White paper, Symantec. https://www.symantec.com/content/en/ us/enterprise/media/security_response/whitepapers/w32_stuxnet dossier.pdf. Accessed 5 June 2018

147. Slay J, Miller M (2007) Lessons learned from the maroochy water breach. In: International conference on critical infrastructure protection. Springer, Boston, pp 73-82. https://doi.org/10.1007/9780-387-75462-8 6

148. Yampolskiy M, Horvath P, Koutsoukos XD, Xue Y, Sztipanovits J (2013) Taxonomy for description of cross-domain attacks on CPS. In: Proceedings of the 2nd ACM international conference on high confidence networked Systems, pp 135-142. https://doi.org/10. 1145/2461446.2461465

149. DeSmit Z, Elhabashy AE, Wells LJ, Camelio JA (2016) Cyberphysical vulnerability assessment in manufacturing systems. Procedia Manufacturing 5:1060-1074. https://doi.org/10.1016/j. promfg.2016.08.075

150. Buckholtz B, Ragai I, Wang L (2016) Remote equipment security in cloud manufacturing systems. Int J Manuf Res 11(2):126-143. https://doi.org/10.1504/IJMR.2016.078245

151. Chhetri SR, Canedo A, Al Faruque MA (2016) Kcad: kinetic cyber-attack detection method for cyber-physical additive manufacturing systems. In: IEEE/ACM International Conference on Computer-Aided Design (ICCAD), Austin, TX, pp 1-8. https://doi.org/10.1145/2966986.2967050

152. Al Faruque MA, Chhetri SR, Canedo A, Wan J (2016) Acoustic side-channel attacks on additive manufacturing systems. In: Proceedings of the 7 th international conference on cyberphysical Systems, Vienna, Austria, pp 19. https://doi.org/10. 1109/ICCPS.2016.7479068

153. Pasqualetti F, Dörfler F, Bullo F (2013) Attack detection and identification in cyber-physical systems. IEEE Trans Autom Control 58(11):2715-2729. https://doi.org/10.1109/TAC.2013.2266831 
154. Teixeira A, Pérez D, Sandberg H, Johansson KH (2012) Attack models and scenarios for networked control systems. In: Proceedings of the 1 st international conference on high confidence networked Systems, Beijing, China, pp 55-64. https://doi.org/10. 1145/2185505.2185515

155. Xu Y, Song R, Korba L, Wang L, Shen W, Lang S (2005) Distributed device networks with security constraints. IEEE Trans Ind Inf 1(4):217-225. https://doi.org/10.1109/TII.2005. 843826

156. Amin S, Cárdenas AA, Sastry SS (2009) Safe and secure networked control systems under denial-of-service attacks. In:
Majumdar R, Tabuada P (eds) Hybrid Systems: computation and control. HSCC 2009. Lecture notes in computer science, vol 5469. Springer, Berlin. https://doi.org/10.1007/978-3-642-006029_3

Publisher's note Springer Nature remains neutral with regard to jurisdictional claims in published maps and institutional affiliations. 